\title{
SINERGIA
}

REVISTA DO INSTITUTO DE CIÊNCIAS ECONÔMICAS, ADMINISTRATIVAS E CONTÁBEIS (ICEAC)

\section{ANÁLISE DAS COMPETÊNCIAS DESENVOLVIDAS E DIFICULDADES ENCONTRAS POR DISCENTES DE CIÊNCIAS CONTÁBEIS ATRAVÉS DO PROBLEM-BASED LEARNING}

\author{
FABIANA KELLY DA SILVA AMORIM \\ CARITSA SCARTATY MOREIRA* \\ JOCYKLEBER MEIRELES DE SOUZA
}

\begin{abstract}
Esta pesquisa tem por objetivo analisar as competências desenvolvidas e dificuldades encontradas por discentes de Ciências Contábeis através do Problem-Based Learning (PBL), como uma proposta de ensino-aprendizagem nas disciplinas de Auditoria e Perícia Contábil da Universidade Federal Rural do Semi-Árido (UFERSA). Para tanto, a unidade de análise foi composta por 68 alunos matriculados nas disciplinas de Auditoria I, Auditoria II e Perícia Contábil que tinham por base o método tradicional de ensino. Quanto aos aspectos metodológicos, utilizou-se da estatística descritiva para as perguntas fechadas, e da análise de conteúdo para as respostas discursivas. Os principais resultados evidenciaram que a aplicação do PBL proporciona conhecimentos, sejam novos ou derivados de outras disciplinas já estudadas durante o curso. Quanto às habilidades listadas pelos discentes, destacam-se a solução de problemas, a comunicação e o trabalho em equipe. Já em relação às atitudes, destacaram a colaboração e o interesse na execução das tarefas. Entretanto, os discentes listaram algumas dificuldades encontradas quanto à aplicação do método, como a falta de clareza nas etapas, estrutura física, tempo de aplicação, falta de colaboração dos membros, reconhecimento de diferentes pontos de vista e aversão ao método.
\end{abstract}

RESUMO

Palavras-chave: Conhecimentos, Habilidades e Atitudes. Problem-Based Learning. Ensino de Contabilidade.

\section{ABSTRACT}

This research aims to analyze the skills developed and difficulties encountered by students of Accounting Sciences through Problem-Based Learning (PBL), as a teaching-learning proposal in the subjects of Auditing and Accounting Expertise at the Federal Rural University of the Semi-Arid (UFERSA). For this purpose, the unit of analysis was composed of 68 students enrolled in the subjects of Audit I, Audit II and Accounting Expertise, which were based on the traditional teaching method. As for the methodological aspects, descriptive statistics were used for closed questions, and content analysis for discursive answers. The main results showed that the application of PBL provides knowledge, whether new or derived from other disciplines already studied during the course. As for the skills listed by the students, problem solving, communication and team work stand out. Regarding attitudes, they highlighted collaboration and interest in carrying out tasks. However, the students listed some difficulties encountered regarding the application of the method, such as the lack of clarity in the steps, physical structure, time of application, lack of collaboration from members, recognition of different points of view and aversion to the method.

Keywords: Knowledge, Skills and Attitudes. Problem-based learning. Accounting Teaching.

Recebido em: 25-06-2020 Aceito em: 12-08-2020

\section{INTRODUÇÃO}

O curso de graduação em Ciências Contábeis deve possibilitar formação profissional que revele diversas competências e habilidades, conforme orienta a Resolução CNE/CES no 10 de 16 de dezembro de 2004, s, como a elaboração de pareceres e relatórios independente dos modelos organizacionais, assim como deve desenvolver, analisar, implantar sistemas de informação contábil e de controle gerencial, além de demonstrar capacidade crítica para analisar as implicações organizacionais com a tecnologia da informação.

Entretanto, apesar da resolução ser bem clara quanto ao perfil do profissional que deve ser formado, isto é, a necessidade do desenvolvimento de diversas competências, como a capacidade crítica acerca de situações, de trabalhar em equipes, comunicação e liderança, Soares (2008) destaca que, no contexto brasileiro, o curso de Ciências Contábeis tem focado no conhecimento técnico do aluno, sendo que essa

\footnotetext{
"Bacharel em Ciências Contábeis pela Universidade Federal Rural do Semi-Árido.

" Doutoranda em Ciências Contábeis pela Universidade Federal da Paraíba.

"*** Mestre em Universidade Federal do Rio Grande do Norte. E-mail: jocykleber@live.com
} 
característica não é suficiente para o bom desempenho do profissional no mercado.

Segundo Freire (2009), ainda se apresenta de forma muito característica no processo de ensino, a ideia de que o professor é o detentor do saber, e, portanto, o professor irá transmitir conhecimentos ao aluno e este, por sua vez, deve memorizá-los, internalizá-los e repeti-los, mecanicamente, desenvolvendo uma relação desigual, quanto ao poder e à autonomia, sendo o professor considerado o sujeito ativo do processo de ensino-aprendizagem.

A teoria construtivista preconiza que o aluno passe pelo processo de construção do conhecimento por meio da interação entre o sujeito e o objeto. Portanto, o conhecimento se origina numa zona intermediária entre sujeito e objeto, em que o professor assume o papel de facilitador e mediador da aprendizagem, sem desprestigiar a perspectiva do discente (PONTES et al., 2006).

Diante desse cenário, tem-se o Problem-Based Learning (PBL), caracterizando-se como um método de ensino-aprendizagem que está centrado no aluno como sujeito ativo. É caracterizado pelo uso de problemas reais da sociedade, contextualizados de forma que o aluno desenvolva as competências necessárias para o sucesso profissional. Encontra-se fundamentado em uma metodologia educacional construtivista, que procura conciliar teoria e prática, preparando o aluno para o mercado de trabalho (RIBEIRO, 2010).

De acordo com Cardoso et al. (2010), a competência representa um conjunto de virtudes do indivíduo em determinada atividade que o tornam capaz de resolver determinada situação, sendo ela composta por uma tríade denominada de Conhecimentos, Habilidades e Atitudes (CHA). Nesse sentido, verifica-se que a combinação dos elementos do CHA, podem integrar a nota do discente, e, por mais que seus elementos sejam distintos, eles possuem uma atuação sinérgica. Nesse processo, faz-se necessário compreender cada um dos seus elementos que se relaciona diante do saber (conhecimento), saber fazer (habilidade) e querer fazer (atitude) (FREZATTI el al., 2016).

De acordo com Frezatti et al. (2016), A importância do método PBL no processo de ensinoaprendizagem, de acordo com Moreira et al. (2018), confirma-se mediante a verificação da literatura, uma vez que diversas pesquisas já foram desenvolvidas sobre a utilização do método no ensino contábil das Instituições de Ensino Superior (IES), assim como sobre as estratégias utilizadas na condução do método (FREZATTI; SILVA, 2014), e até sobre o processo avaliativo (FREZATTI et al., 2016).

Ante o exposto, considerando o processo de ensino tradicional, o método PBL e CHA, elaborou-se o seguinte problema de pesquisa: qual a percepção dos discentes de ciências contábeis acerca das competências desenvolvidas e dificuldades encontradas através do Problem-Based Learning (PBL) como uma proposta de ensino/aprendizagem em uma universidade de ensino tradicional?

Para responder ao questionamento proposto acima, adotou-se como objetivo analisar as competências desenvolvidas e dificuldades encontradas por discentes de Ciências Contábeis através do Problem-Based Learning (PBL) como uma proposta de ensino-aprendizagem nas disciplinas de Auditoria e Perícia Contábil da Universidade Federal Rural do Semi-Árido (UFERSA).

A presente pesquisa justifica-se por realizar uma investigação sobre a aplicação do PBL em uma universidade de ensino tradicional, bem como a análise dos conhecimentos, das habilidades e das atitudes, desenvolvidas pelos discentes, podendo contribuir para a melhoria do processo de ensino da contabilidade na referida universidade, ou em outras que adotam o método tradicional. Além disso, a pesquisa também demonstra relevância ao analisar as dificuldades encontradas pelos discentes em relação ao método, possibilitando o aprimoramento da prática de ensino-aprendizagem baseada em problemas.

\section{REFERENCIAL BIBLIOGRÁFICO}

\subsection{Problem-Based Learning e o Desenvolvimento dos Conhecimentos, Habilidades e Atitudes}

A técnica PBL surge como proposta de aprendizagem construtivista, focada nos alunos e não no professor; assim, sua execução vem mostrando a relevância para o ensino dos discentes, tendo como objetivo formar profissionais da contabilidade com competências adequadas às demandas de mercado indo além do mero caráter de informação transmitida pela forma do ensino tradicional (CELESTINO et al., 2016).

O processo de ensino e aprendizagem pelo método PBL, segundo Frezatti e Silva (2014), proporciona a ligação do educando com a prática, seja inserindo ou realizando intervenções na realidade da área de formação. As apreciações metodológicas são organizadas através das indagações que envolvem os fenômenos ou projetos e requer dos envolvidos uma investigação, reflexão sobre o aspecto delimitado e a comunicação das observações e resultados, logo agrega o tripé: prática profissional, pesquisa e ensino (FREZATTI; SILVA, 2014).

As etapas que estão relacionadas à execução do PBL são divididas em sete passos: (I) ponto de partida: ler atenciosamente o problema/tema e esclarecer os termos incomuns, (II) tempestade de ideias: interligar abertamente ideias relacionadas ao cenário do tema/problema, (III) sistematização: definição de 
deduções/proposições, (IV) formulação de questões de aprendizagem: questões que contribuam na resolução do problema, (V) estabelecer metas de aprendizagem: formular objetivos que proporcionem dar resposta às indagações e o plano de ação para realizar, (VI) avaliação do processo: avaliação do processo e da aprendizagem, (VII) seguimento: desfazer enganos, analisar metas de aprendizagem e seguir adiante (PINTO et al., 2004).

Dentro desse contexto, verifica-se a relação de ensino aprendizagem no PBL que é realizado pela união de três elementos primordiais, sendo eles: o problema, o aluno e o professor (MARTINS; FREZATTI, 2015). O primeiro deles é a parte central do processo, aonde os estudantes trabalham com o objetivo de solucioná-lo, dentro de uma determinada circunstância. O segundo seria o aluno, responsável pela busca ativa do conhecimento; e o terceiro, o tutor (professor), responsável por auxiliar os aprendizes nas dificuldades de conteúdo da disciplina e do problema (FREZATTI; SILVA, 2014).

Para Martins et al. (2015), é notória a falta de preparo do discente para realizar pesquisas, não estando este adaptado a apresentar uma postura ativa no contexto escolar que proporcione reflexões acerca do conhecimento, sendo essa resistência uma característica do ensino tradicional.

O objetivo de introduzir no ensino contábil não só os conhecimentos técnicos necessários, como também as habilidades e as atitudes do profissional exigidas pelo mercado, provoca um choque no processo de ensino tradicional, sendo necessário desfazer a relação de poder do professor para com os estudantes, compondo assim uma relação de facilitador (MARTINS; FREZATTI, 2015).

Nesse sentido, o CHA pode ser visto como uma ferramenta importante no processo de ensinoaprendizagem. De acordo, com Santaella e Rodrigues (2015), o conhecimento atual, útil e produtivo, pode ser considerado como o "saber", já a habilidade em se relacionar, adquirir resultados e desenvolver tarefas, está associada a "saber fazer", enquanto a atitude criativa, como ser ética ou ter iniciativa, está ligada a "querer fazer". Essa combinação é sinergicamente uma união, por mais que seus elementos sejam distintos, eles possibilitam condições de identificar se o discente apresentou o conhecimento programado (FREZATTI et al., 2016).

\subsection{Estudos Correlacionados ao Tema}

Verifica-se que as pesquisas nacionais e internacionais, acerca do PBL no ensino em contabilidade, vêm discutindo a implementação, bem como, o processo avaliativo da metodologia aplicada em sala, as suas características as estratégias a serem utilizadas para manter o interesse do discente perante a disciplina com aplicação desse método, além da sua utilização nas IES.

Manaf, Aziah e Wan-Hussin (2011) verificaram os benefícios da utilização do PBL no ensino, para tanto, utilizou uma turma de Contabilidade Financeira. Como resultados, constatou que o método do PBL apresentou benefícios significativos em capacidade de comunicação, trabalho em equipe e liderança em relação a metodologia tradicional.

Stanley e Mansden (2012) analisaram a implementação e o desenvolvimento do PBL. De acordo com os dados coletados com discentes de Ciências Contábeis, constatou-se a eficácia do método, principalmente no desenvolvimento de habilidade de questionamento, trabalho em equipe e resolução de problemas.

Duncan, Smith e Cook (2013) investigaram o uso do PBL de forma on-line em uma turma de pósgraduação em contabilidade. Concluindo que o método desenvolveu competências de avaliação de dados, criatividade e senso crítico. Por outro lado, o ambiente virtual apresentou-se como uma dificuldade a aplicação do método.

Frezatti e Martins (2016) tiveram como propósito tratar a questão da customização de técnicas alternativas do PBL nos cursos de graduação e de especialização. A investigação empírica aconteceu por meio da comparação de estudos de caso em disciplinas de controle gerencial. De acordo com os achados, foi possível constatar que a aplicação do PBL não deve ser feita de uma única maneira, mas sim, com formatos diferentes da abordagem do PBL, observando a maturidade dos alunos, a complexidade dos elementos considerados, o tempo disponível para a disciplina e do objetivo em si.

Azevedo et al. (2017) objetivaram identificar os conhecimentos, habilidades e atitudes desenvolvidas pelos discentes de Contabilidade por meio da Aprendizagem Baseada em Projetos (ABP) na disciplina Orçamento Empresarial. Dentre os principais resultados, observaram que os principais conhecimentos adquiridos pelos discentes com aplicação da ABP ocorreram nas áreas contábil e gerencial, as habilidades que apresentaram um maior desenvolvimento foram o trabalho em equipe, o planejamento e a visão sistêmica, já as atitudes foram o comprometimento, a proatividade e respeito pela opinião dos outros.

Wilkin (2017) analisou a implementação do PBL em uma disciplina de sistemas da informação no curso de Contabilidade. Os resultados demonstraram uma influência positiva da metodologia no desenvolvimento acadêmico, por meio do envolvimento dos discentes com a experiência de aprendizagem, as modificações curriculares abordadas, possibilitaram o desenvolvimento comunicacional, reflexivo e crítico dos estudantes. 
Moreira et al. (2018) tiveram por propósito analisar as competências desenvolvidas e dificuldades encontradas na aplicação do PBL sob a ótica dos discentes. Os principais resultados evidenciaram que os alunos relataram diversas competências desenvolvidas por meio do método PBL. São elas: pensamento crítico, trabalho em equipe, capacidade de compreender e resolver problemas, aprendizagem autônoma, reconhecer diferentes pontos de vista, planejamento, liderança, interdisciplinaridade. Por outro lado, descrevem que sentiram dificuldades em aspectos relacionados à estrutura física, aversão ao método, ao estudo autônomo, à falta de orientação do tutor, à falta de clareza das etapas do PBL, ao tempo de aplicação, nível de desestruturação do problema e à falta de colaboração dos membros.

\section{ASPECTOS METODOLÓGICOS}

A presente pesquisa caracteriza-se como qualitativa quanto à abordagem do problema, descritiva quanto ao objetivo proposto, e estudo de caso quanto aos procedimentos utilizados. De acordo com Yin (2015), o estudo de caso é um método de pesquisa que tem como destaque a sua forma de análise, pois foca na profundidade do fenômeno estudado, permitindo, assim, análises mais detalhadas acerca dos conhecimentos, das habilidades e das atitudes desenvolvidas pelos discentes

Porém, Yin (2015) recomenda que sejam utilizados estudos de casos múltiplos, quando possível, em detrimento de casos únicos, uma vez que os primeiros permitem resultados mais robustos, menos enviesados. Considerando essas recomendações, para esta pesquisa, optou-se por realizar o estudo em três turmas de graduação do curso de Ciências Contábeis na terceira unidade das disciplinas de Auditoria I, Auditoria II e Perícia Contábil, correspondendo ao 6ำ, $7^{\circ}$ e $8^{\circ}$ períodos, sendo todas as turmas noturnas, totalizando 68 alunos: 23 alunos de Auditoria I, 24 de Auditoria II, e 21 de Perícia. Ressalta-se que todas as turmas foram selecionadas pelo critério de acessibilidade.

Cabe ressaltar que a aplicação do PBL nas três turmas foi do tipo post-holding, isto é, o PBL foi aplicado em disciplinas que tem por base aulas expositivas, de cunho tradicional (RIBEIRO, 2010). Ainda a referida aplicação foi realizada na terceira unidade de cada disciplina, que ocorreu durante os meses de agosto e setembro de 2018, totalizando nove aulas em cada turma. Desse modo, as aulas que até a segunda unidade eram realizadas da forma tradicional, ou seja, com aulas expositivas, resolução de exercícios e provas, passaram na terceira unidade a ser realizada por meio do PBL, aplicando-se um caso prático acerca da temática das disciplinas que levava em consideram os conhecimentos prévios dos alunos.

Para a coleta de dados, utilizou-se a observação participante e um questionário elaborado com base na literatura, composto por perguntas objetivas e subjetivas que foram respondidas pelas três turmas de graduação ao final da aplicação do PBL. Os discentes precisaram identificar os conhecimentos, as habilidades e as atitudes que foram desenvolvidas, bem como, as dificuldades percebidas durante a aplicação do método.

Após a aplicação dos questionários aos alunos, os dados primários relativos às questões fechadas foram compilados para um arquivo do software Microsoft Excel, para que fossem tratados por meio da estatística descritiva. Já para as questões abertas foram transcritas para um arquivo digital, para que fosse adotada a técnica de análise de conteúdo. De acordo com Bardin (2011), essa última técnica refere-se a um conjunto de técnicas de análise das comunicações que permitam a inferência de conhecimentos relativos às condições de produção/recepção destas mensagens.

A utilização do software ATLAS.ti® permitiu realizar a codificação aberta acerca das respostas discursivas dos discentes, que, por sua vez, tratavam sobre as dificuldades percebidas pelos mesmos durante o processo de aplicação do PBL. De acordo com Flick (2009), o processo de codificação aberta consiste em identificar conexões, códigos e categorias presentes em cada resposta aberta. No caso desta pesquisa, a codificação permitiu identificar unidades de significado de acordo com as dificuldades listas pelos discentes.

\section{ANÁLISE DOS RESULTADOS}

Essa seção apresenta a análise dos dados obtidos por meio do questionário aplicado, que foi dividida em duas partes, a saber: (i) Desenvolvimento do CHA pelos discentes; e (ii) As dificuldades encontradas na aplicação do PBL sob a ótica dos discentes.

\subsection{Desenvolvimento do CHA pelos discentes}

Por meio dessa seção é apresentado a investigação acerca das habilidades, dos conhecimentos e as atitudes desenvolvidas pelos discentes. Desse modo, a Tabela 1 apresenta os conhecimentos (10 elemento do $\mathrm{CHA}$ ) desenvolvidos pelos respondentes com a aplicação da metodologia em forma de Ranking, uma vez que foram requeridos a atribuírem uma nota de 0 a 10 para cada conhecimento listado. 
Tabela 1 - O desenvolvimento do Conhecimento

\begin{tabular}{|c|c|c|}
\hline Ranking & Conhecimento & Total \\
\hline $1^{0}$ & Auditoria Contábil & 609 \\
\hline $2^{0}$ & Legisl. Social e trabalhista & 514 \\
\hline $3^{\circ}$ & Fundamentos de administração & 450,3 \\
\hline $4^{0}$ & Prática Contábil I & 438,5 \\
\hline $5^{\circ}$ & Contabilidade Introdutória & 435,5 \\
\hline $6^{\circ}$ & Metodologia científica & 394,5 \\
\hline $7^{0}$ & Cont. Intermediária II & 387,5 \\
\hline $8^{0}$ & Cont. Intermediária I & 383,2 \\
\hline 9움 & Perícia Contábil & 370,3 \\
\hline $10^{\circ}$ & Teoria das organizações & 359 \\
\hline $11^{\circ}$ & Prática Contábil II & 338 \\
\hline $12^{0}$ & Teoria da contabilidade & 336,9 \\
\hline $13^{0}$ & Tópicos da Informática & 335,8 \\
\hline $14^{\circ}$ & Análise das Demons. Contábeis & 317,8 \\
\hline $15^{\circ}$ & Direi. Com. e Trib. & 294,9 \\
\hline $16^{\circ}$ & Contabilidade de Custos & 293 \\
\hline $17^{\circ}$ & Sistemas de Inf. Contábeis & 292,5 \\
\hline $18^{\circ}$ & Prática Contábil III & 290,5 \\
\hline $19^{\circ}$ & Análise de Custos & 289,8 \\
\hline $20^{\circ}$ & Sociologia das Organizações & 287,5 \\
\hline $21^{\circ}$ & Administração Financeira & 285,3 \\
\hline $22^{0}$ & Contabilidade Avançada & 284 \\
\hline $23^{\circ}$ & Fundamentos da Matemática & 281 \\
\hline $24^{\circ}$ & Conta. Tributária & 265,3 \\
\hline $25^{\circ}$ & Matemática Financeira & 246 \\
\hline $26^{\circ}$ & Teoria Econômica & 244,2 \\
\hline $27^{\circ}$ & Inst. de Dir. Pub. e Priv. & 234,9 \\
\hline $28^{\circ}$ & Finanças Corporativas & 221,7 \\
\hline $29^{\circ}$ & Estatística & 217 \\
\hline $30^{\circ}$ & Contab. Governamental & 182,3 \\
\hline $31^{\circ}$ & Economia Brasileira & 157,5 \\
\hline $32^{0}$ & Cont. e Gestão do Agr. & 113,7 \\
\hline $33^{0}$ & Contabilometria & 84,8 \\
\hline $34^{\circ}$ & Comercio de Prod. no Agronegócio & 75,7 \\
\hline $35^{\circ}$ & Noções de Dir. Agr & 53,5 \\
\hline
\end{tabular}

Percebe-se que áreas com mais destaque entre os discentes foi a Auditoria Contábil e a Legislação Social e Trabalhista. A possível justificativa para esse resultado pode ser derivada do problema utilizado para que os discentes buscassem soluções para ele, pois, considerando o contexto das disciplinas, o problema proposto foi de fraude contábil presente nos demonstrativos das folhas de pagamento de uma empresa. Desse modo, devido à atuação da auditoria no contexto das fraudes, e a maior parte dos discentes analisados foram das disciplinas de Auditoria, é justificável a predominância do conhecimento acerca dessa temática. Além disso, a percepção dos discentes acerca dos conhecimentos desenvolvidos foi confortado com os resultados obtidos em sala de aula, através da observação participante e da entrega do relatório final, constatou-se um desempenho satisfatório dos alunos em tais áreas.

Contudo, o que fica evidenciado é que a aplicação do PBL permite a interdisciplinaridade entre as diversas áreas do conhecimento, uma vez que possibilita a formação e a utilização do conhecimento adquirido de forma holística. Nesse contexto, Moreira et al. (2018) afirmam que é na formação do profissional contábil, importante não só obter novos conhecimentos, mas também retomar conteúdos estudados anteriormente. 
Tabela 2 - O desenvolvimento da habilidade

\begin{tabular}{c|c|c}
\hline Ranking & Habilidade & Total \\
\hline $1^{0}$ & Solução de problema & 642,2 \\
\hline $2^{\underline{0}}$ & Comunicação & 642,4 \\
\hline $3^{0}$ & Trabalho em equipe & 641,4 \\
\hline $4^{0}$ & Análise crítica & 621,4 \\
\hline $5^{0}$ & Planejamento & 618,4 \\
\hline $6^{0}$ & Visão sistêmica & 614 \\
\hline $7^{0}$ & Desenvolvimento do projeto & 606,7 \\
\hline $8^{0}$ & Criatividade e inovação & 601,8 \\
\hline $9^{0}$ & Trabalho autorregulado & 600,5 \\
\hline $1^{0}$ & Interdisciplinaridade & 588,9 \\
\hline $1^{\circ}$ & Estudo independente & \\
\hline
\end{tabular}

Fonte: Dados da pesquisa (2019)

Por meio da Tabela 2 é possível observar o desenvolvimento das habilidades $\left(2^{\circ}\right.$ elemento do $\mathrm{CHA}$ ) conforme a percepção dos discentes e organizadas em forma de ranking. Nota-se que todas as habilidades listadas nessa pesquisa apresentaram nota alta. $O$ destaque vai para as três primeiras colocadas, solução de problemas e a comunicação e o trabalho em equipe. Moreira et al. (2018) consideraram como competências a capacidade de compreender e resolver problemas e o trabalho em equipe. Os autores destacam que a rotina do profissional da contabilidade exige, a partir de um cenário empresarial, a necessidade de identificar os problemas, compreendê-los e, então, identificar as diversas formas de solução para aquele proposto, bem como, que o profissional contábil constantemente utilize da ajuda de outros colegas de profissão, sejam porque trabalham juntos ou mesmo porque algum possui uma especialização em um determinado assunto.

Analisando a habilidade que ficou em último no ranking, nota-se que foi resultado de estudo independente. Isso corrobora os resultados, até aqui evidenciados, de que os discentes não possuem a autonomia em relação ao desenvolvimento de tarefas, seja na sala de aula ou pelos estudos extraclasse. Tal fato mostra que, apesar de o método proporcionar essa autonomia, ainda assim, foi à habilidade menos desenvolvida de acordo com a percepção dos estudantes analisados.

Tabela 3 - O desenvolvimento da atitude

\begin{tabular}{c|c|c}
\hline Ranking & Atitude & Total \\
\hline $1^{0}$ & Colaboração e cooperação & 638,9 \\
\hline $2^{\underline{0}}$ & Interesse & 638 \\
\hline $3^{0}$ & Proatividade & 633,9 \\
\hline $4^{0}$ & Ética & 633,9 \\
\hline $5^{0}$ & Respeitar opinião dos outros & 633,4 \\
\hline $6^{0}$ & Curiosidade & 629,9 \\
\hline $7^{0}$ & Empatia & 627,4 \\
\hline $8^{0}$ & Experiência & 626,9 \\
\hline $9^{0}$ & Comprometimento & 625 \\
\hline $1^{0}$ & Flexibilidade & 609,4 \\
\hline
\end{tabular}

Fonte: Dados da pesquisa (2019)

A Tabela 3 evidencia as atitudes ( $2^{\circ}$ elemento do $\left.\mathrm{CHA}\right)$ desenvolvidas, de acordo com a percepção dos discentes. Conforme pode ser observado pelos resultados, assim como as habilidades, as atitudes desenvolvidas com o método receberam nota alta. Percebe-se que as que mais se destacam foram à colaboração/cooperação e o interesse na realização das tarefas, sendo estes de fundamental importância para a solução do problema proposto pelo tutor (professor), consequentemente, aquele que ajuda na preparação dos futuros profissionais para os desafios a serem enfrentados quando do exercício das atividades.

Por outro lado, a flexibilidade ficou na última colocação, demonstrando a dificuldade por parte dos discentes em relação à compreensão e à aceitação diante de mudanças, ou seja, de novos pensamentos e ideias, o que pode, no contexto profissional, dificultar a implantação de novas estratégias. 


\subsection{Dificuldades encontradas na aplicação do PBL sob a ótica dos discentes}

$\mathrm{Na}$ execução do método PBL, foram percebidas algumas dificuldades, apontadas pelos discentes. Os que foram identificadas de acordo com as respostas discursivas foram: a falta de clareza nas etapas, a estrutura física, o tempo de aplicação, a falta de colaboração dos membros, o reconhecimento de diferentes pontos de vista e a aversão ao método.

Nesse contexto, de acordo com a Fig. 1, a falta de clareza nas etapas do PBL foi listada como uma dificuldade percebida durante a aplicação do método, o que proporcionou certa insegurança aos discentes, visto que o pouco conhecimento sobre o método causa dificuldades na execução deste, derivado de muitas informações novas, mas que foi possível superar após novos encontros em sala de aula. De acordo com Frezatti e Silva (2014), a falta de clareza quanto às etapas do método PBL podem causar alguns problemas, considerando fundamental a repetição do cronograma de atividade a cada aula.

Figura 1 - Dificuldade quanto à falta de clareza nas etapas do PBL

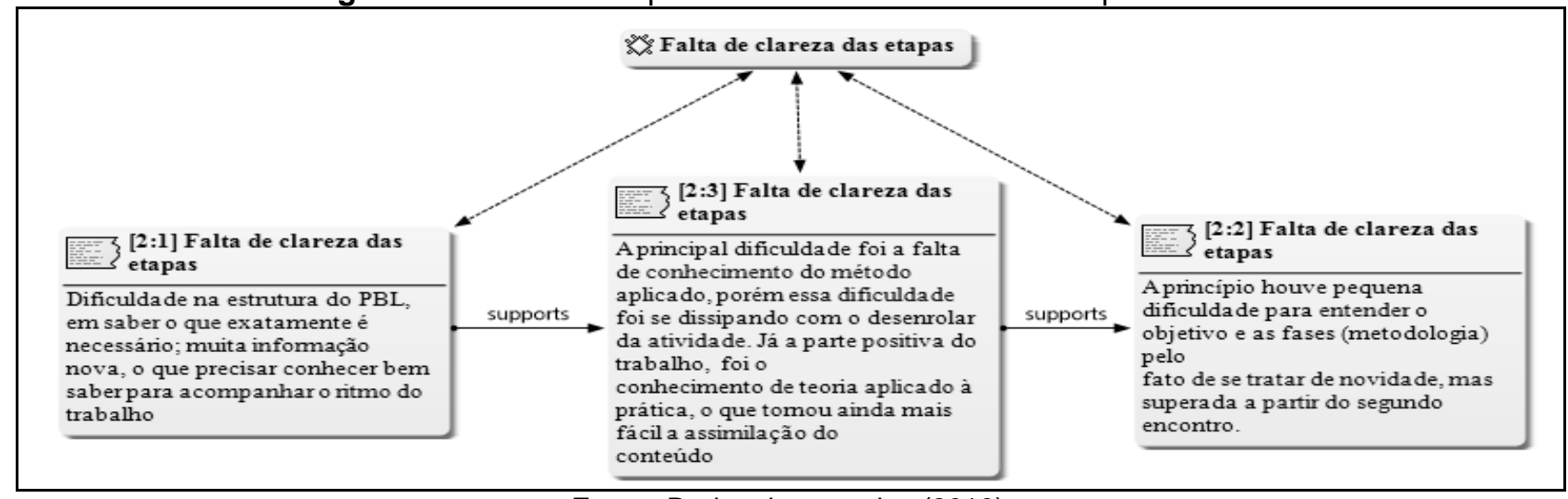

Fonte: Dados da pesquisa (2019)

Conforme a Fig. 2, a estrutura física também foi definida como uma dificuldade observada pelos alunos, uma vez que diversos problemas foram listados, como o tamanho da sala, a quantidade de tomadas disponíveis insuficientes, e ausência de computadores, percebe-se que o ambiente onde as atividades do PBL são desenvolvidas pode trazer prejuízos durante a sua aplicação para o processo de ensinoaprendizagem dos alunos. No estudo de Moreira et al. (2018), os discentes também destacaram a estrutura física como uma dificuldade na execução do método, considerando que a sala de aula em que estava não era adequada.

Figura 2 - Dificuldade quanto a estrutura Física

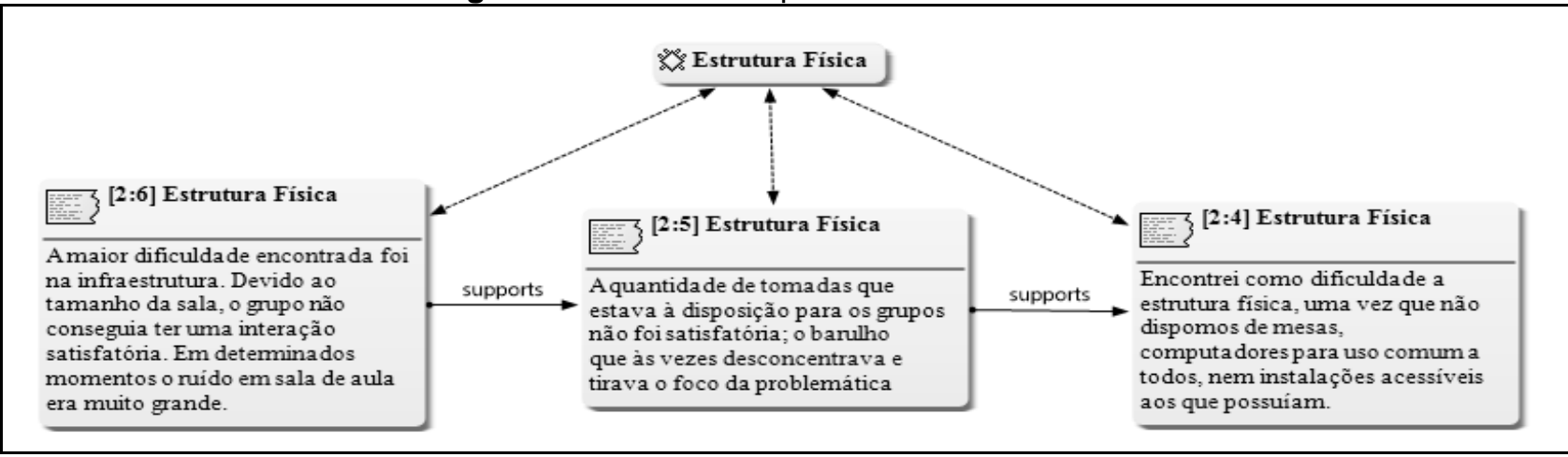

Fonte: Dados da pesquisa (2019)

De acordo com a Fig. 3, destaca-se, também, o tempo de aplicação como uma dificuldade enfrentada pelos discentes, uma vez que foi considerado curto. Apesar de os discentes afirmarem que foi um método proveitoso, os mesmos destacaram a dificuldade que tiveram em cumprir o cronograma apresentado, visto que eram muitas informações novas a serem absorvidas. Souza e Dourado (2015) afirmam que uma das barreiras enfrentadas pelo método é o tempo, pois é impossível desempenhar a concepção de entendimento tão rápida quanto no método tradicional, dizem ainda que ser fundamental um tempo maior para que seja possível uma aprendizagem satisfatória e com isso os discentes se sentirão mais seguros em relação à informação obtida. 
Figura 3 - Dificuldade quanto o tempo de aplicação do PBL

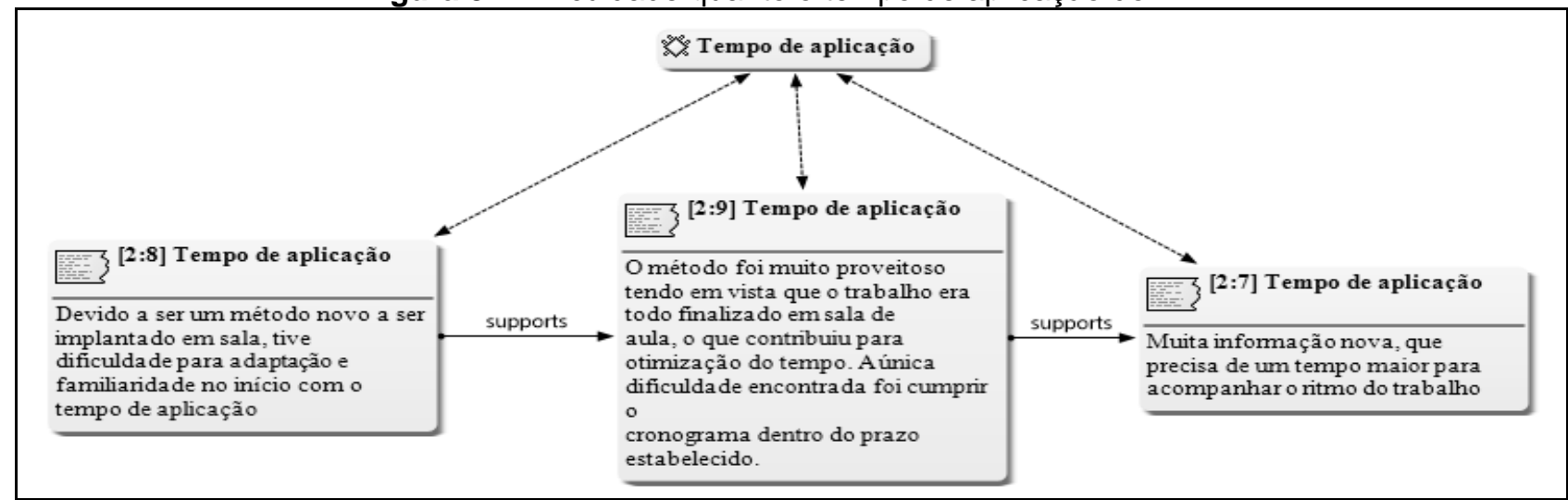

Fonte: Dados da pesquisa (2019)

Para os discentes a falta de colaboração entre os membros do grupo foi uma das dificuldades encontradas, conforme demonstra a Fig. 4. De acordo com os relatos dos alunos, a falta de ritmo da equipe, a dificuldade na comunicação, a ausência nas aulas, foram os motivos principais para a deficiência na colaboração dos membros. Como o PBL é desenvolvido em equipes, observa-se que essa dificuldade está interligada a outras como o tempo de aplicação, visto que a falta de colaboração dos membros acaba dificultando o ritmo do trabalho e, consequentemente, o processo de aprendizagem interdisciplinar.

De acordo com Souza e Dourado (2015), o trabalho em grupo proporciona um aprendizado interdisciplinar e solidário, fazendo também os discentes meditarem em relação aos métodos tradicionais analisando até que momento esse método proporciona uma melhor aprendizagem.

Figura 4 - Dificuldade quanto à falta de colaboração dos membros

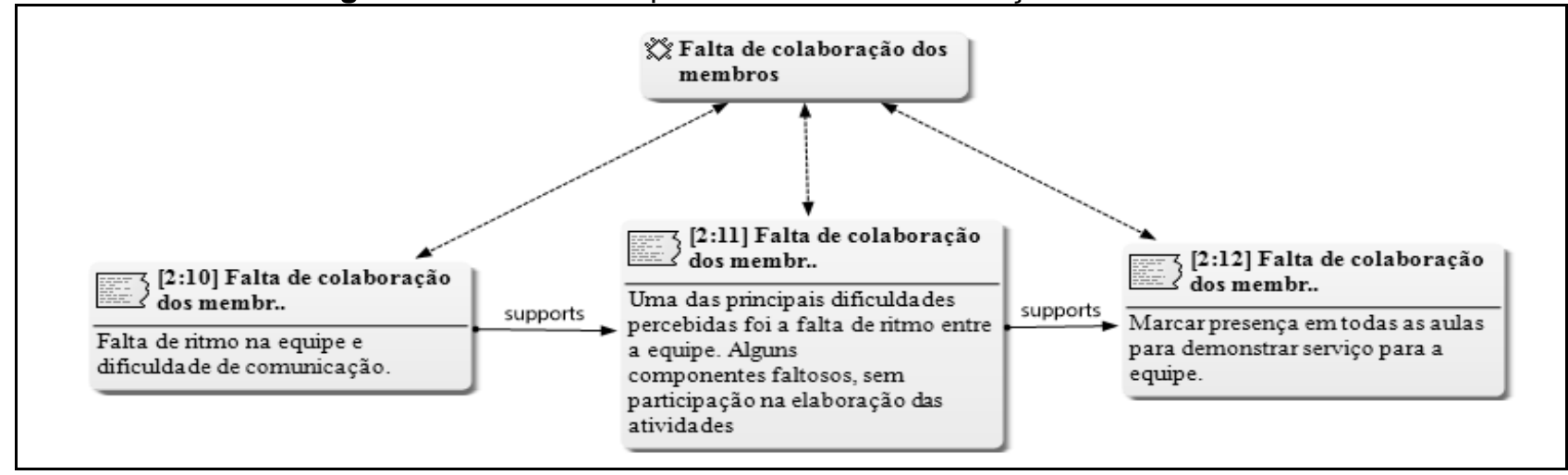

Fonte: Dados da pesquisa (2019)

De acordo com a Fig. 5, ficou evidenciada a existência de dificuldades como a divergência de opiniões, que de fato impossibilita a chegada a um consenso entre o grupo, gerando uma problemática quanto ao desempenho que deve ser esperado pelo grupo de discentes. De acordo com Beck e Rausch (2014) a dificuldade apresentada no estudo independente se dá pela presença forte do ensino tradicional, que, apesar de muitos docentes atualmente defenderem o processo ensino-aprendizagem, tendo o discente como ponto central desta aquisição, o ensino tradicional, no qual o docente é o dono do saber, ainda está muito presente nas instituições de ensino.

Figura 5 - Dificuldade em reconhecer diferentes pontos de vista

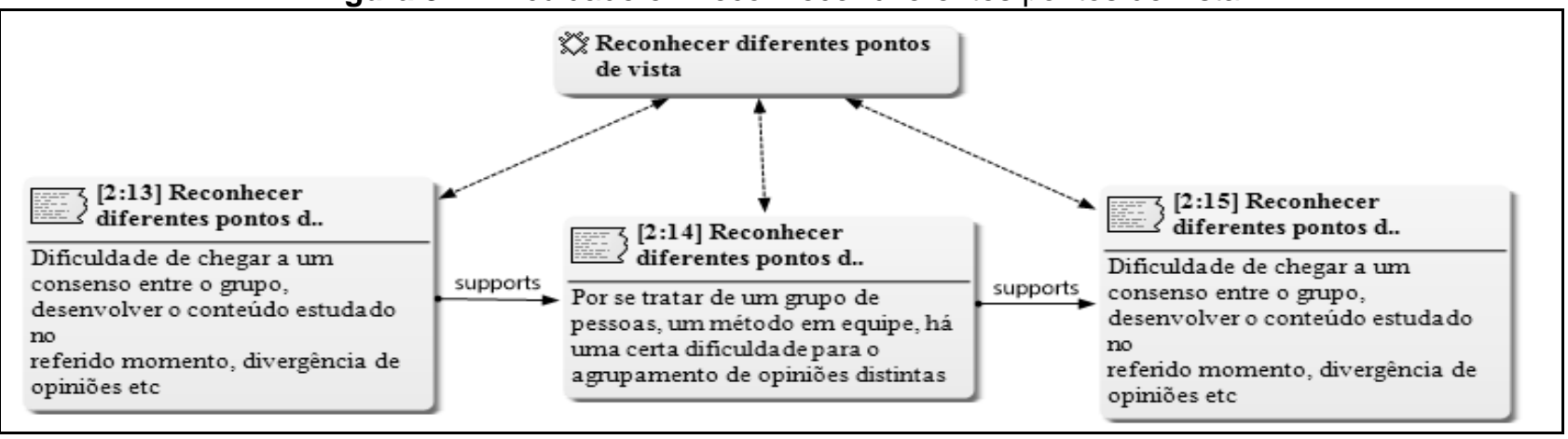

Fonte: Dados da pesquisa (2019) 
Na Fig. 6, percebe-se que a dificuldade quanto à implantação do PBL está relacionada ao fato de ser algo novo que traz uma nova visão quanto ao processo de ensino-aprendizagem, acarretando problemas de adaptação para os discentes. Diante dessa exposição de opiniões fica evidenciada a dificuldade quanto ao aprendizado por meio de métodos novos, mesmo que estes venham a trazer melhorias, pois o convencional ficou convencionado, proporcionando certo conforto e estabilidade.

Figura 6 - Dificuldade derivada de aversão ao método

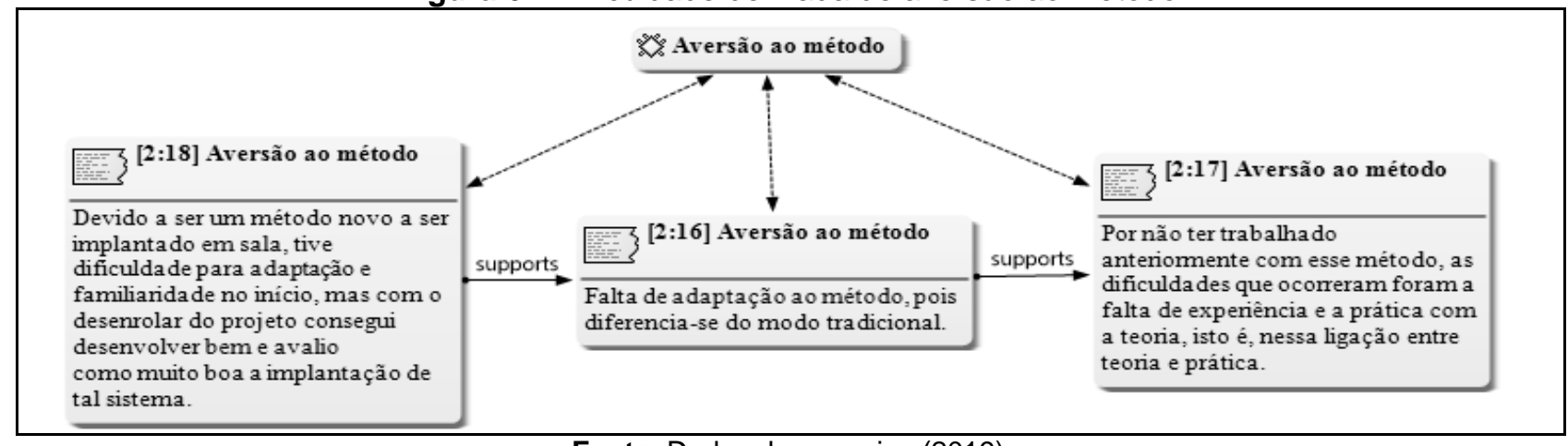

Fonte: Dados da pesquisa (2019)

Pelas dificuldades apresentadas pelos discentes, percebe-se que a aversão diante do PBL, por se tratar de algo novo e que inicialmente causaria dificuldade para adaptação, pode ser a causa de outras dificuldades, como a organização do tempo, trabalho em equipe, e reconhecimento de diferentes pontos de vista, por exemplo. Entretanto, enfatizaram Moreira et al. (2018) que essas diversas dificuldades percebidas pelos discentes podem se transformar em competências que auxiliarão o futuro profissional no desempenho de suas tarefas. Ainda destacam que essa reversão pode ser concretizada por meio da correta orientação do tutor, de uma estrutura física adequada, e do constante enfoque de que o PBL pode proporcionar melhorias para o processo ensino-aprendizagem dos discentes.

\section{CONCLUSÃO}

O presente estudo teve por objetivo analisar o as competências desenvolvidas e dificuldades encontradas por discentes de Ciências Contábeis através do Problem-Based Learning (PBL) como uma proposta de ensino-aprendizagem nas disciplinas de Auditoria e Perícia Contábil da UFERSA. Para alcançar o objetivo proposto, utilizou-se de um questionário como coleta de dados que aplicados nas disciplinas de Auditoria I, Auditoria II e Perícia Contábil da referida universidade, cujas disciplinas tinham por base as aulas expositivas. Adicionalmente, por meio de uma pergunta aberta do questionário, os discentes puderam discorrer sobre as dificuldades percebidas durante a aplicação do método.

Assim, de acordo com a percepção dos alunos, a aplicação do PBL proporciona o desenvolvimento de diversas habilidades, destacando entre elas, a solução de problemas, a comunicação e o trabalho em equipe, apesar de todas as listadas receberem nota alta, como análise crítica, visão sistêmica, e criatividade e inovação.

Pelas atitudes desenvolvidas, nota-se que todas listadas receberam nota alta, destacando-se a colaboração e o interesse na execução das tarefas. Como o PBL é um método focado no trabalho em equipe, os discentes afirmaram ter desenvolvido essa atitude, o que é considerado bom para o contexto da formação profissional, tendo em vista que ao trabalharem em conjunto, precisam demonstrar interesse e emprenho para o sucesso na execução das tarefas.

Apesar de o PBL ser considerado um método que proporciona bons resultados para o processo de ensino-aprendizagem dos alunos, após sua aplicação, os discentes listaram algumas dificuldades, como falta de clareza nas etapas, estrutura física, tempo de aplicação, falta de colaboração dos membros, reconhecimento de diferentes pontos de vista e aversão ao método.

Por fim, diante do exposto, acredita-se que o PBL obteve êxito com a sua aplicação em uma universidade de ensino tradicional, cuja constatação foi possível por meio da análise dos conhecimentos, das habilidades e das atitudes que os discentes afirmaram ter desenvolvido. Nesse sentido, acredita-se que o PBL demonstrou sua eficácia quando aplicado em disciplinas de caráter teórico, como Auditoria e Perícia Contábil, que, por vezes, dificulta a ligação com a prática.

Como limitações, esta pesquisa apresentou a impossibilidade de realização de entrevistas com os discentes que participaram da execução do método, tanto em virtude da quantidade de alunos, quanto devido à aplicação do método ter sido no final do semestre, ocorrendo à dispersão dos mesmos. Assim, sugere-se para pesquisas futuras, a realização de entrevistas e/ou grupos focais com os discentes a fim de 
dar mais consistência aos achados. Ademais, cabe realizar essa mesma aplicação em diferentes disciplinas com o intuito de verificar as competências desenvolvidas e até as dificuldades percebidas.

\section{REFERÊNCIAS}

AZEVEDO, Y. G. P.; ARAúJO, A. O.; MEDEIROS, V. C.; Conhecimentos, Habilidades e Atitudes Desenvolvidas Pelos Discentes de Contabilidade Através da Aprendizagem Baseada em Projetos. Contabilidade, Gestão e Governança. v. 20, n. 1, 2017.

BARDIN, L.; Análise de conteúdo. 1. ed. São Paulo: Almedina, 2011.

BECK, F.; RAUSCH, R. B.; Fatores que influenciam o processo ensino-aprendizagem na percepção de discentes do Curso de Ciências Contábeis. Contabilidade Vista \& Revista, Belo Horizonte, v. 25, n. 2, p. 38-58, 2014.

BRASIL; Resolução CNE/CES no 10, de 16 de dezembro de 2004. Institui as Diretrizes Curriculares Nacionais para o Curso de Graduação em Ciências Contábeis, bacharelado, e dá outras providências. Diário Oficial [da] República Federativa do Brasil. Conselho Nacional de Educação. Câmara de Educação Superior. Brasília, DF, 28 dez. 2004.

CELESTINO, E. J. M.; AZEVEDO, Y. G. P.; ARAÚJO, A. O.; SILVA, J. D. G.; Problem-based-learning (PBL) nos cursos de ciências contábeis das instituições de ensino superior (IES) de Natal/RN. In:Congresso da Associação Nacional de Programasde Pós-Graduação em Ciências Contábeis, 10, São Paulo. Anais eletrônicos... São Paulo: ANPCONT, 2016.

DUNCAN, Michael J.; SMITH, Mike; COOK, Kathryn. Implementing online problem based learning (PBL) in postgraduates new to both online learning and PBL: An example from strength and conditioning. Journal of Hospitality, Leisure, Sport \& Tourism Education, n. 12, p. 79-84, 2013.

FLICK, U.; Introdução à pesquisa qualitativa. Porto Alegre: Artmed. Links, 2009.

FREIRE, P.; Pedagogia da autonomia: saberes necessários à prática educativa. 39a ed. São Paulo: Paz e Terra, 2009. FREZATTI, F.; SILVA, S. C.; Prática versus incerteza: como gerenciar o estudante nessa tensão na implementação de disciplina sob o prisma do método pbl? Revista Universo Contábil, Blumenau, v. 10, n. 1, p. 28-46, jan./mar. 2014.

FREZATTI, F.; BORINELLI, M. L.; MARTINS, D. B.; ESPEJO, M. M. S.B.; Análise do desempenho de alunos na perspectiva do "CHA" em disciplina utilizando PBL: o que significa a síntese? Revista de Contabilidade e Organizações, São Paulo, v. 10, n. 26, p. 3-19, 2016.

FREZATTI, F.; MARTINS, D. B. Pbl ou Pbl's: a customização do mecanismo na educação contábil. Revista de Graduação da USP, São Paulo v.1, n.1, p. 25-34, jul. 2016.

MANAF, Abdul; AZIAH, Nor; WAN-HUSSIN, Wan Nordin. Application of Problem Based Learning (PBL) in a course on financial accounting principles. Malaysian Journal of Learning and Instruction, n. 8, p. 21-47, 2011

MARTINS, D. B.; ESPEJO, M. M. S.; FREZATTI, F.; Problem-Based Learning no Ensino de Contabilidade Gerencial: Relato de uma Experiência Brasileira. Revista de Educação e Pesquisa em Contabilidade, v. 9, n. 4, p. 430-452, out/dez. 2015.

MOREIRA, C. S.; SOUZA, J. M.; ARAÚJO, A. O.; AZEVEDO, Y. G. P.; Problem-Based Learning: Uma Análise das Competências Desenvolvidas e Dificuldades Encontradas sob a Ótica dos Discentes de Contabilidade. In: International Conference in Accouting, 18, 2018, São Paulo. Anais...São Paulo, 2018.

PINTO, G. R. P. R.; SANTOS, C. A. S.; PEREIRA, H. B. B.; AVPBL: uma ferramenta para auxiliar a sessão tutorial do método de Aprendizagem Baseada em Problemas. In: Congresso Nacional de Ambientes Hipermídia para Aprendizagem, 2004. Anais...Florianópolis, 2004.

PONTES, A.L.; REGO, S.; SILVA JÚNIOR, A.G.; Saber e prática docente na transformação do ensino médico. Revista Brasileira de Educação Médica, v. 30, n. 2, p. 66-75, 2006.

RIBEIRO, L. R. C.; Aprendizagem baseada em problemas (PBL):uma experiência no ensino superior. $1^{\text {a }}$ ed. São Carlos: EduFSCAR, 2010.

SANTAELLA, L.; RODRIGUES, J.; Reflexões sobre conhecimentos, habilidades e atitudes necessárias ao corretor de imóveis. In: Congresso Nacional de Gestão em Excelência, Rio de Janeiro. Anais... Rio de Janeiro, 2015.

SOARES, M. A.; Aplicação do método de ensino problembasedlearning (PBL) no curso de ciências contábeis: um estudo empírico. Tese de Doutorado. Universidade de São Paulo, 2008.

SOUZA, S. C.; DOURADO L.; Aprendizagem baseada em problemas (ABP): um método de aprendizagem inovador para o ensino educativo. Revista HOLOS, Rio Grande do Norte, v. 5, n. 31, p. 182 - 200, 2015.

STANLEY, T.; MARSDEN, S.; Problem-based learning: Does accounting education need it?. Journal of Accounting Education, v. 30, n. 3-4, p. 267-289, 2012.

WILKIN, C.L.; Enhancing critical thinking: accounting students' perceptions. Education+ Training, v. 59, n. 1, p. 15-30, 2017.

YIN, R. K. Estudo de Caso: Planejamento e métodos. Bookman editora, 2015. 